\title{
Invited Response on: Use of an Orbital Septum Flap for Correcting Severe Blepharoptosis
}

\author{
Shogo Kasai ${ }^{1}$ (D)
}

Received: 7 September 2021 / Accepted: 11 September 2021/Published online: 5 October 2021

(C) Springer Science+Business Media, LLC, part of Springer Nature and International Society of Aesthetic Plastic Surgery 2021

Level of evidence $V$ This journal requires that authors assign a level of evidence to each article. For a full description of these Evidence-Based Medicine ratings, please refer to the Table of Contents or the online Instructions to Authors www.springer.com/00266

To the Editor,

We sincerely thank Zhang and Wang for their interest in our article "Use of an Orbital Septum Flap for Correcting Severe Blepharoptosis" [1] and for bringing further attention to this important and complex topic. They raise several important points.

First and foremost, the strength of the orbital septum flap is something we carefully considered. As noted, the orbital septum alone can be thin and lack in mechanical strength. We therefore raise a complex flap that includes not only the orbital septum but also retro orbicularis oculi fat and the fibrous connective tissue that surrounds it. This results in a flap in which the caudal side may be weak but the cranial side is solid in thickness and strength. When performing this procedure for severe ptosis, the caudal side of the flap is excised, and we have not encountered significant trouble with fixation. We concur that caution is required in some cases and agree that longer follow-up time would add to the strength of our observations. As pointed out, all of the patients included in our study were Asian. This is the population that we serve and it is unlikely that we would have the opportunity to apply and study

Shogo Kasai

kasai_sh@hotmail.com

1 Department of Plastic Surgery, Ryukyu University School of Medicine, 207 Uehara Nishihara-cho Nakagami-gun, Okinawa 903-0215, Japan this technique outside of an Asian population. Therefore, the effectiveness of this technique in the Caucasian eyelid warrants further study.

Finally, the typical levator advancement procedure, which is now widely used in surgery for blepharoptosis, involves an incision in the orbital septum but less invasion of the flaps used in our method. Therefore, secondary surgery after a typical levator advancement has not been difficult. However, it is expected to be difficult depending on the method of initial surgery. We acknowledge the likely challenge of revision surgery in a case operated on by a different surgeon and also that one may encounter situations where this method cannot be used.

\section{Declarations}

Conflicts of Interest The authors declare that they have no conflict of interest.

Human and animal rights This article does not contain any studies with human participants or animals performed by any of the authors. For this type of study, informed consent is not required.

\section{Reference}

1. Kasai S, Shimizu Y, Ohara H et al (2021) Use of an Orbital Septum Flap for Correcting Severe Blepharoptosis. Aesth Plast Surg 45:1593-1600. https://doi.org/10.1007/s00266-020-02087-1

Publisher's Note Springer Nature remains neutral with regard to jurisdictional claims in published maps and institutional affiliations. 